\title{
An Assessment of Heavy Metal Contamination in the Nakdong River Around the Weir
}

\author{
Hee Won Son (D), Sun Hee Shim (D, Haeseong Oh (D) and Jung Hyun Choi *D \\ Department of Environmental Science and Engineering, Ewha Womans University, 52, Seoul 03760, Korea; \\ gmldnjs@ewhain.net (H.W.S.); sunhee960@ewhain.net (S.H.S.); hs1226@ewhain.net (H.O.) \\ * Correspondence: jchoi@ewha.ac.kr; Tel.: +82+2-3277-6686
}

Citation: Son, H.W.; Shim, S.H.; Oh, H.; Choi, J.H. An Assessment of Heavy Metal Contamination in the Nakdong River Around the Weir. Water 2021, 13, 684. https://doi.org/ 10.3390/w13050684

Academic Editor: Bulgariu Laura

Received: 14 January 2021

Accepted: 1 March 2021

Published: 3 March 2021

Publisher's Note: MDPI stays neutral with regard to jurisdictional claims in published maps and institutional affiliations.

Copyright: (c) 2021 by the authors. Licensee MDPI, Basel, Switzerland. This article is an open access article distributed under the terms and conditions of the Creative Commons Attribution (CC BY) license (https:// creativecommons.org/licenses/by/ $4.0 /)$.
Abstract: In this study, the concentrations and characteristics of copper $(\mathrm{Cu})$, zinc $(\mathrm{Zn})$, and lead $(\mathrm{Pb})$ contamination in sediment samples were investigated using aqua regia extraction and Tessier's five-step sequential extraction. Based on the concentration of metals, the influence of the HapcheonChangnyeong weir on sediments in the Nakdong River was assessed. The origins of the contaminants, their bioavailability, and their mobility were determined using sequential extraction. Greater concentrations of heavy metals were found in samples collected closer to the weir. The largest proportion of $\mathrm{Cu}$ was identified in the residual fraction based on sequential extraction, whereas $\mathrm{Zn}$ was predominantly found in the reducible fraction. Iron-manganese in the reducible fraction of $\mathrm{Zn}$ has the potential to leach back to the water body. In addition, the combined concentration of fractions 1 and 2 of $\mathrm{Cu}$ comprised more than $20 \%$ of total amount that still has potential to affect the water quality. The results of this study were compared with existing sediment standards set out by the NIER (National Institute of Environmental Research), Canada, and US EPA (United States Environmental Protection Agency) guidelines, as well as the risk assessment code (RAC). The concentrations of heavy metals exceeded the standards set by the Canadian guideline by up to four times in particular samples, highlighting the need for continual monitoring.

Keywords: heavy metal; surface water quality; aqua regia extraction; sequential extraction; monitoring; water contaminants

\section{Introduction}

Chemical contaminants, such as metals, herbicides, and toxic organic compounds may enter rivers from numerous sources [1]. In contrast to organic pollutants, heavy metals are problematic since they do not biodegrade, threatening the aquatic ecosystem and eventually human health through bioaccumulation [2-5]. In particular, river flow may stagnate around weirs, leading to increased sedimentation of heavy metals. Such heavy metals may subsequently re-enter the water through diffusion and re-suspension, deteriorating the water quality [6]. Therefore, it is necessary to continuously monitor the chemical and physical changes of heavy metals in sediments around weirs [6].

Aqua regia extraction is frequently employed to monitor the concentration of heavy metals in river sediments. However, heavy metals are likely to be released into the water under different environmental conditions, depending on their chemical nature and have varying effects on sediment and water quality. Therefore, the metals must be further partitioned through sequential extraction according to their chemical form $[7,8]$. While sequential extractions are time-consuming, they enhance the understanding of the bioavailability and origins of heavy metals and are often used during water quality management [9]. Among the various sequential extraction techniques, Tessier's method is one of the most well-known methods and enables sediments to be subdivided into five fractions [10]. This method's main advantage is that heavy metal concentrations may be measured after partitioning based on their chemical forms [11]. Originally, Tessier's sequential method was 
developed to examine the concentrations of heavy metals in aquatic sediments. However, its application has been gradually extended to the classification of heavy metals in soil [12].

The Nakdong River is a major river in South Korea that requires continuous monitoring for heavy metals while also differentiating between their chemical forms. Weirs are employed along the Nakdong River to provide both drinking water and water for agricultural and industrial processes in the local region. However, a previous study reported that the concentrations of copper $(\mathrm{Cu})$, zinc $(\mathrm{Zn})$, and lead $(\mathrm{Pb})$ of sediments in the Nakdong River were expected to exceed sediment heavy metal standards due to the presence of several industrial complexes further downstream [13]. Since heavy metals in water tend to remediate quicker than that of sediment, and sediment is one of the ultimate sink of metals even with extremely low concentration, we focused on investigating the heavy metal concentrations of sediments [14,15]. For these reasons, monitoring the concentrations of such metals in the Nakdong River is crucial, particularly in regions of the river with weirs where the water flow is expected to stagnate.

This paper investigates the quantities of $\mathrm{Cu}, \mathrm{Zn}$, and $\mathrm{Pb}$ in sediments retrieved from the Hapcheon-Changnyeong weir (HCW). Their concentrations were measured through the aqua regia extraction method and compared with values obtained from Tessier's five-step sequential method to study correlations and recovery. Furthermore, the origins, bioavailability, and mobility of each metal were studied based on their proportions in each fraction during sequential extraction. The extent of metal contamination in the sediment was evaluated by comparing the obtained concentrations with the standard levels for heavy metals published by the National Institute of Environmental Research (NIER), Canada, and the United States Environmental Protection Agency (US EPA) [16-18] as well as the risk assessment code (RAC). This study's conclusions will be used to monitor the heavy metal contamination in sediment in the HCW and predict their impact on the water and the surrounding ecosystem.

\section{Materials and Methods}

\subsection{Study Area}

This study focused on the sediment found in the HCW on the Nakdong River (South Korea). The HCW, constructed to retain water resources for the Changnyeong and Hapcheon areas, has a total length of $328 \mathrm{~m}$ and a height of $11.5 \mathrm{~m}$. The movable portion of the weir has a length of $138 \mathrm{~m}$, while the fixed portion measures $190 \mathrm{~m}$. The accumulative precipitation of 2019 was $959.8 \mathrm{~mm}$, while the accumulative precipitation from July to September 2019 was $444.6 \mathrm{~mm}$ [19].

\subsection{Sampling Method}

Sediment samples were collected from two locations that were 1 and $5 \mathrm{~km}$ north of the weir, labeled ND1 and ND2, respectively, and shown in Figure 1. These samples were collected in 2019, on 23rd July, 13th August, and 19th September. Since the flow rate of the river affects transportation and accumulation of sediment [20], we sampled from July to September to investigate the effect of flow rate and retention time changed by the precipitation on the sediment.

The sediment was sampled by an experienced diver using an acrylic core (diameter $5 \mathrm{~cm}$, height $22 \mathrm{~cm}$ ) ensuring that the surrounding sediment was not disturbed and carried to the laboratory in an icebox held at $4{ }^{\circ} \mathrm{C}$. Heavy metals were extracted by first drying the upper $2 \mathrm{~cm}$ of the sediment until it reached a constant weight and then sieving the sediment with a $0.5 \mathrm{~mm}$ sieve [21-23]. 


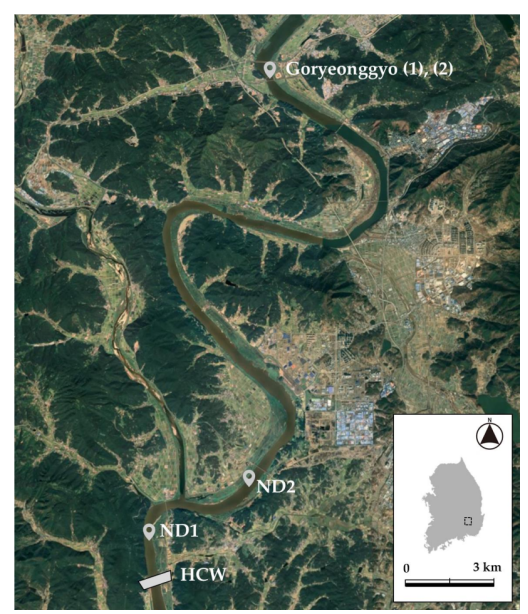

Figure 1. Sampling site (ND1 and ND2), and the locations of previous research (Goryeonggyo (1), (2)) of heavy metals in the Nakdong River.

\subsection{Physical and Chemical Characteristics of the Study Area}

The in situ $\mathrm{pH}$ and Dissolved Oxygen (DO) concentration of water body were measured using a multiparameter instrument (professional plus, YSI, USA). To measure total organic carbon (TOC), the sediment samples were freeze-dried and crushed in an agate mortar, and measured with elemental analyzer (EA 1110, FV instruments, UK) after removing inorganic carbonates with $1.0 \mathrm{~N}$ hydrochloric acid. The particle size was measured by a particle size analyzer (Mastersizer 2000, Malvan, UK) after removing organics and carbonates using $10 \%$ hydro peroxide and $0.1 \mathrm{~N}$ hydrochloric acid [24].

\subsection{Aqua Regia Extraction}

Aqua regia extraction was used to find the total amount of heavy metal in the sediment. Each sample was duplicated for precise result. Aqua regia extraction is used in Germany, the Netherlands, and many other European countries to evaluate sediment contamination [25]. Aqua regia consists of 35-37\% hydrochloric acid and $60 \%$ nitric acid in a 3:1 ratio [26,27]. A total of $1 \mathrm{~g}$ of dried sediment was stirred with $10 \mathrm{~mL}$ aqua regia, first at $40^{\circ} \mathrm{C}$ for $1 \mathrm{~h}$ and subsequently at $140^{\circ} \mathrm{C}$ for $4 \mathrm{~h}$, per previously reported methods [28]. The solution was then vacuum filtered, and the filtrate was diluted with distilled water to $100 \mathrm{~mL}$. The concentrations of $\mathrm{Cu}, \mathrm{Zn}$, and $\mathrm{Pb}$ were measured using inductively coupled plasma atomic emission spectroscopy (ICP-OES) (ICP-5800, Agilent, USA). Analysis was performed by the National Instrumentation Center for Environmental Management (NICEM) at Seoul National University, South Korea (https:/ / nicem.snu.ac.kr, accessed on 19 February 2021). The calibration was done with reference solution produced by Inorganic Ventures (https:/ / www.inorganicventures.com, accessed on 19 February 2021), and the $R^{2}$ values were 0.999 for $\mathrm{Cu}, \mathrm{Pb}$, and $\mathrm{Zn}$. The detection limit is $0.001 \mathrm{mg} / \mathrm{L}, 0.003 \mathrm{mg} / \mathrm{L}$, and $0.001 \mathrm{mg} / \mathrm{L}$ for $\mathrm{Cu}, \mathrm{Pb}$, and $\mathrm{Zn}$, respectively.

\subsection{Sequential Extraction}

To study each chemical fraction of heavy metal, we employed the five-step sequential method devised by Tessier and later modified by Yong $[8,11,29,30]$. In the fifth step, aqua regia was used rather than perchloric acid or hydrofluoric acid to verify the result of aqua regia extraction and sequential extraction. Samples were duplicated. The five steps involve sequentially combining the heavy metals with (1) exchangeable ions, (2) carbonates, (3) ironmanganese oxides, (4) sulfides and organics, and (5) residual metals, which are bound to lithogenic minerals, to achieve extraction and quantification [31,32]. Exchangeable ions, carbonates, and iron-manganese oxides usually represent heavy metals that are derived from anthropogenic sources. Anthropogenic sources typically exhibit high bioavailability 
and readily leach into the water [33]. On the other hand, residuals consist of heavy metals with low bioavailability and mobility $[9,32]$.

Each of the five extraction steps is detailed below. Note that the effluent leached from each step was filtered using Whatman 40 filter paper, made up to $100 \mathrm{~mL}$ diluted with distilled water, and then was processed in the next extraction step. (1) Exchangeable ions were extracted from $1 \mathrm{~g}$ of dried sample in $8 \mathrm{~mL}$ of $1 \mathrm{M} \mathrm{MgCl}_{2}$ adjusted to $\mathrm{pH} 7$ with $\mathrm{CH}_{3} \mathrm{COOH}$ for one hour at room temperature. (2) Carbonates were extracted in $8 \mathrm{~mL}$ of $1 \mathrm{M} \mathrm{CH}_{3} \mathrm{COOH}$ adjusted to $\mathrm{pH} 5$ with $\mathrm{CH}_{3} \mathrm{COOH}$ and stirred for $5 \mathrm{~h}$ at room temperature. (3) Iron-manganese oxides were extracted in $20 \mathrm{~mL}$ of $0.04 \mathrm{M} \mathrm{NH}_{2} \mathrm{OH} \cdot \mathrm{HCl}$ diluted with $25 \% \mathrm{CH}_{3} \mathrm{COOH}$ at $95{ }^{\circ} \mathrm{C}$. (4) Sulfides and organics were extracted in $3 \mathrm{~mL}$ of $0.02 \mathrm{M} \mathrm{HNO}_{3}$ and $2 \mathrm{~mL}$ of $30 \% \mathrm{H}_{2} \mathrm{O}_{2}$ and held at $85^{\circ} \mathrm{C}$ for $2 \mathrm{~h}$. An additional $3 \mathrm{~mL}$ of $30 \% \mathrm{H}_{2} \mathrm{O}_{2}$ was subsequently added, and the solution was stirred for a further $3 \mathrm{~h}$. Finally, $7 \mathrm{~mL}$ of distilled water and $5 \mathrm{~mL}$ of $3.2 \mathrm{M} \mathrm{CH}_{3} \mathrm{COONH}_{4}$ diluted with $20 \% \mathrm{HNO}_{3}$, which was diluted with distilled water, were added and stirred for $30 \mathrm{~min}$ at room temperature. (5) Residuals were extracted using $10 \mathrm{~mL}$ of aqua regia for one hour at $40^{\circ} \mathrm{C}$ and four hours at $140{ }^{\circ} \mathrm{C}$ (Figure 2). The concentrations of extracted metals were measured using ICPOES (ICP-5800, Agilent) with the same method mentioned in 2.4 Aqua Regia Extraction.

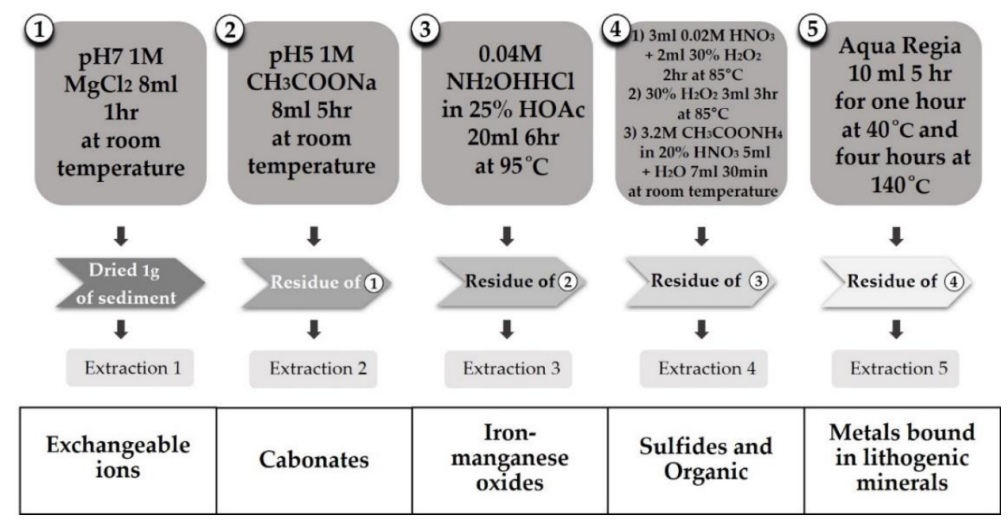

Figure 2. Tessier's five-step extraction flow chart.

\subsection{Risk Assessment Code}

The RAC is a widely applied to evaluation of heavy metal mobility and bioavailability. Since heavy metals with high bioavailability might enter aquatic animals and plants, they are considered as an important environmental issue [33]. The RAC is calculated by the ratio of the exchangeable fraction and carbonate fraction to the sum of all fractions, and is expressed as a percentage [34,35]. Since the exchangeable fraction and carbonate fraction of heavy metal are easily leached to the water body, the RAC evaluates the mobility and bioavailability of heavy metals [34]. The code is categorized into five classes (Table 1).

Table 1. Risk Assessment Code Categorization.

\begin{tabular}{ccc}
\hline Class & Risk Assessment Code (\%) & Degree of Risk \\
\hline I & RAC $\leq 1$ & No risk \\
II & $1<$ RAC $\leq 10$ & Light risk \\
III & $10<\mathrm{RAC} \leq 30$ & Medium risk \\
IV & $30<\mathrm{RAC} \leq 50$ & High risk \\
V & RAC $>50$ & Very high risk \\
\hline
\end{tabular}

\section{Results}

\subsection{Environmental Characteristics of the Study Area}

The particle size of sediment influences the concentration of heavy metals [36] and was measured at locations ND1 and ND2. Hydrological factors such as water depth, precipitation, and retention time can affect sediment formation and were also measured. 
The water depths were found to be independent of the sampling date and measured to be $4.0-6.0 \mathrm{~m}$ at ND1 and 6.7-6.8 $\mathrm{m}$ at ND2, as shown in Table 2 .

Table 2. Environmental Characteristics of the Study Area.

\begin{tabular}{ccccccc}
\hline Point & Month & Depth(m) & Sand(\%) & Silt(\%) & Clay(\%) & TOC(\%) \\
\hline \multirow{3}{*}{ ND1 } & July & 4.0 & 92.40 & 6.12 & 1.48 & 2.80 \\
& August & 6.0 & 68.21 & 26.76 & 5.03 & 0.23 \\
& September & 5.1 & 17.86 & 63.67 & 18.47 & 3.57 \\
\hline \multirow{3}{*}{ ND2 } & July & 6.8 & 94.09 & 4.69 & 1.22 & 0.11 \\
& August & 6.7 & 95.79 & 3.72 & 0.49 & 0.19 \\
& September & 6.8 & 92.58 & 6 & 1.42 & 0.15 \\
\hline
\end{tabular}

Due to the monsoon climate in South Korea, most rainfall is concentrated between July and August, while it is not expected to have high volume of precipitation during September. The precipitation and outflow of the weir during these months are shown in Figure 3. Significant volumes of precipitation and outflow had occurred immediately before our first sample collection in July. In contrast, inflow and outflow volumes were comparatively lower during August. The flow rate of the river influences on transportation and accumulation of sediment [20]. Thus, the flow rate and retention time are considered as important environmental factors, which affect the quality of the sediment. The retention time is calculated by dividing the volume of the waterbody by the volume of inflow. The data used for calculating the retention time were collected over 28 days before the sampling, provided by Korea Water Resource Corporation [19]. The average retention times during July, August, and September were found to be 2.25, 2.31, and 2.75 days, respectively. According to previous research, the retention time of the HCW increased 2 to 12 -fold compared with the retention time before the HCW construction, which shows the possible flow rate decrease around the HCW [37]. The $\mathrm{pH}$ remained vertically constant in the water body, which ranged from 7.32-9.01, and the DO of overlying water remained oxic, over $6 \mathrm{mg} / \mathrm{L}$, at both locations (ND1, ND2) during the sampling period. The TOC and particle size composition are also presented in Table 2. For the case of ND1, the TOC concentrations in July and September were $2.80 \%$ and $3.57 \%$, respectively. However, TOC concentration in August was $0.23 \%$. For the case of ND2, the TOC concentration difference from July to September was negligible.

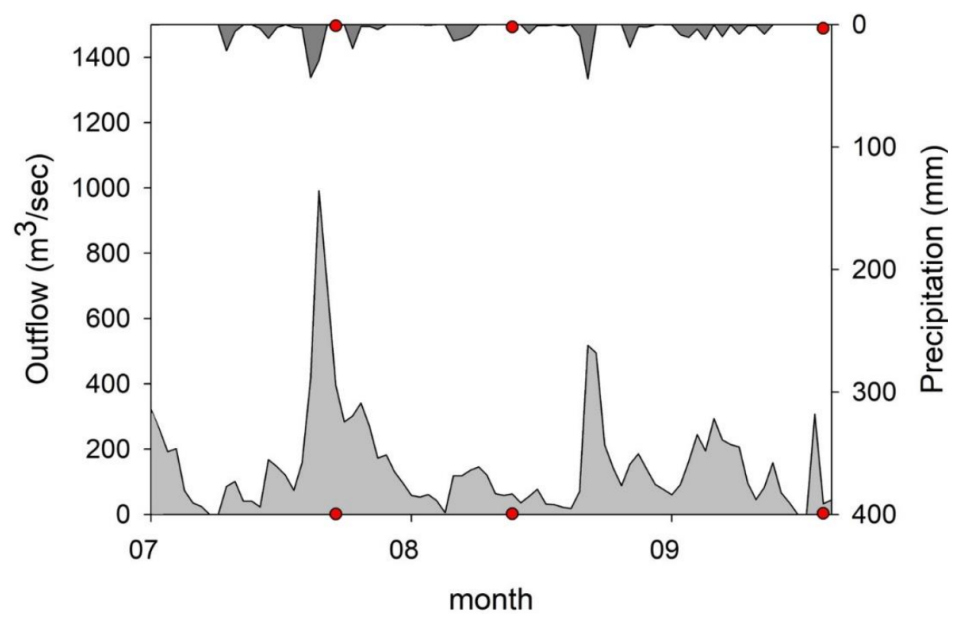

Figure 3. The amounts of outflow and precipitation. The red points indicate the dates on when samples were collected.

The particle sizes changed drastically at ND1. The amount of silt and clay had increased at ND1, while sand composition decreased. The sudden increase in TOC concentration in September at ND1 could be explained with the significant increase in silt and 
clay composition. However, at ND2, the change of particle size distribution was negligible, which corresponds with the TOC concentration.

\subsection{Aqua Regia Extraction}

The total concentration of $\mathrm{Cu}, \mathrm{Zn}$, and $\mathrm{Pb}$ in the sediment samples through aqua regia extraction are shown in Figure 4. Zn exhibited the highest average concentration over the three months of observation, while $\mathrm{Pb}$ demonstrated the lowest. Furthermore, the concentrations of each metal were found to be higher at location ND1 than at ND2. Cu concentrations at ND2 were calculated to be $43.71 \%, 88.32 \%$, and $38.97 \%$ of the values obtained at ND1 during July, August, and September, respectively (Figure 4a). The corresponding percentages for $\mathrm{Zn}$ concentrations were $17.70 \%, 97.27 \%$, and $15.74 \%$ (Figure $4 \mathrm{~b}$ ), while they were $19.93 \%, 95.83 \%$, and $14.37 \%$ for $\mathrm{Pb}$ (Figure $4 \mathrm{c}$ ). The differences in concentration between ND1 and ND2 were especially significant in July and September. These results can be attributed to ND1's closer proximity to the weir than ND2, where the water flow is expected to slow to a greater extent. In turn, this is likely to increase the accumulation of heavy metals in the sediment around the weir [6].

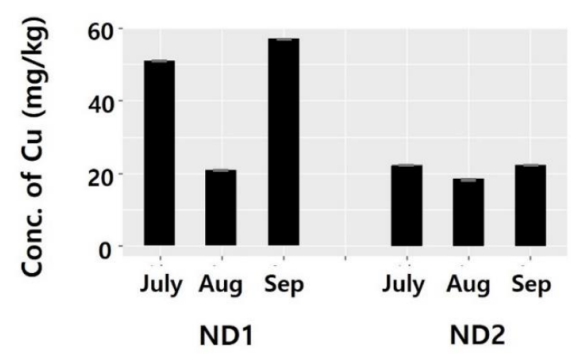

(a)

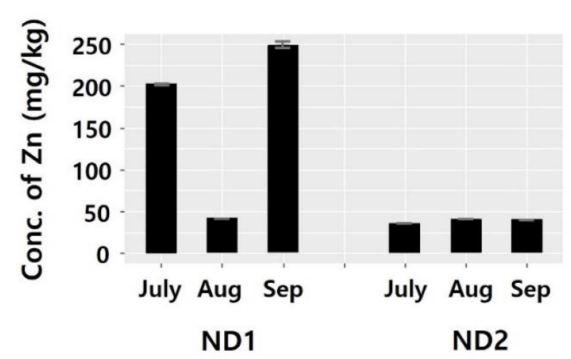

(b)

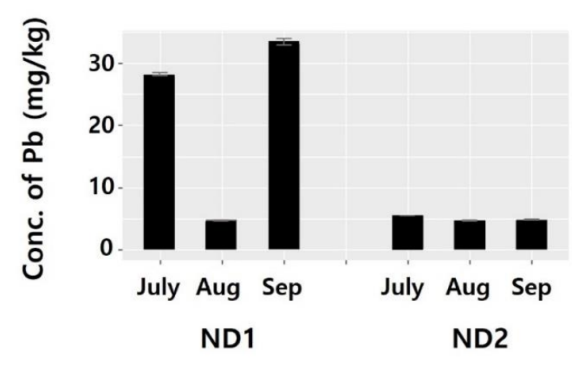

(c)

Figure 4. Concentration of (a) $\mathrm{Cu},(\mathbf{b}) \mathrm{Zn}$, and (c) $\mathrm{Pb}$ in sediment samples from the $\mathrm{HCW}$, analyzed by aqua regia extraction.

Previous studies that have reported $\mathrm{Cu}, \mathrm{Zn}$, and $\mathrm{Pb}$ concentrations in the Nakdong River before the construction of the HCW are summarized in Table 3. The locations of two of the studies are marked in Figure 1, according to the numbering in Table 3. The heavy metal concentrations reported in these studies were lower than our values, as shown in Table 3. Therefore, this further suggests that the weir impacts the water flow and worsens the content of heavy metals in the sedimentation. 
Table 3. Concentration of the heavy Metals before the dam construction.

\begin{tabular}{|c|c|c|c|c|}
\hline & Characteristic & Concent & ls (mg/kg) & Reference \\
\hline \multirow{3}{*}{$(1)$} & \multirow{3}{*}{ Stangnant flow Sampled in 2005} & $\mathrm{Cu}$ & 15.24 & \multirow{3}{*}[32]{} \\
\hline & & $\mathrm{Zn}$ & 80.44 & \\
\hline & & $\mathrm{Pb}$ & 33.47 & \\
\hline \multirow{3}{*}{ (2) } & \multirow{3}{*}{ Sampled before 2000} & $\mathrm{Cu}$ & 6.42 & \multirow{3}{*}[38]{} \\
\hline & & $\mathrm{Zn}$ & 34.77 & \\
\hline & & $\mathrm{Pd}$ & 9.87 & \\
\hline \multirow{3}{*}{ (3) } & \multirow{3}{*}{ Sampled in 1997} & $\mathrm{Cu}$ & 19.38 & \multirow{3}{*}{ [39] } \\
\hline & & $\mathrm{Zn}$ & - & \\
\hline & & $\mathrm{Pb}$ & 22.50 & \\
\hline
\end{tabular}

\subsection{Sequential Extraction}

Sequential extraction was performed on each sediment sample obtained from ND1 and ND2 between July and September to investigate the concentrations of heavy metals in each chemical form. The results of $\mathrm{Pb}$ are not presented since the measured concentrations in some fractions were below the detection limit. The total $\mathrm{Cu}$ and $\mathrm{Zn}$ concentrations across the five extraction steps were evaluated to be $17.90-59.83$ and $40.50-251.90 \mathrm{mg} / \mathrm{kg}$. The concentrations of $\mathrm{Cu}$ and $\mathrm{Zn}$ obtained through sequential extraction were $110.35 \%$ and $133.12 \%$ of the values obtained using aqua regia extraction, respectively.

Sequential extraction showed similar trends regarding the total concentration of $\mathrm{Cu}$ and $\mathrm{Pb}$ with aqua regia extraction. Their concentrations were found to be higher during July and September than during August. Since the 10-day accumulative inflow of August was approximately $50 \%$ and $75 \%$ of July and September, it is expected that less amount of heavy metals flowed into the river [40]. For the case of ND1, the August Cu concentration corresponds to $49 \%$ and $39 \%$ of the July and September Cu concentrations, respectively. Similarly, at ND2, the August Cu concentration corresponded to $58 \%$ and $71 \%$ of the July and September $\mathrm{Cu}$ concentrations, respectively. In addition, the $\mathrm{Zn}$ concentrations measured at ND1 and ND2 during August were 22\% (21\%) and 50\% (90\%) of the values measured in July (September), respectively. This results corresponded with the results of TOC. For the case of ND1, TOC in August was lower than that of July and September. The results of TOC and metal concentration of ND1 is similar with previous research [41,42]. This indicates the possible impact of weir to the sedimentation of pollutants especially when the accumulative inflow volume is significant.

To ensure that the sequential extraction results were valid, the total concentrations of heavy metal obtained from the aqua regia extraction and Tessier's sequential extraction were correlated through linear regression, as shown in Figure 5. The gradients obtained for $\mathrm{Cu}$ (Figure 5a) and Zn (Figure 5b) concentrations were 0.92 and 1.04, respectively, with corresponding $R^{2}$ values of 0.95 and 0.96 . The fact that the $R^{2}$ values approach unity for both metals indicates that the relationship between the two techniques is statistically significant. Furthermore, gradients of approximately 1 indicate that the results from sequential extraction are comparable to those from aqua regia extraction.

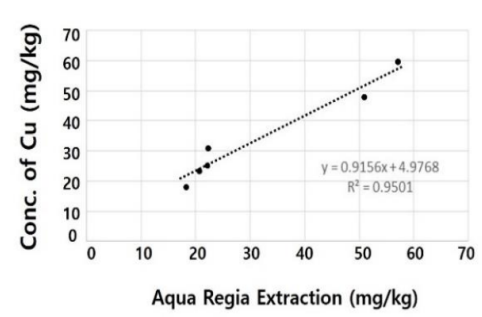

(a)

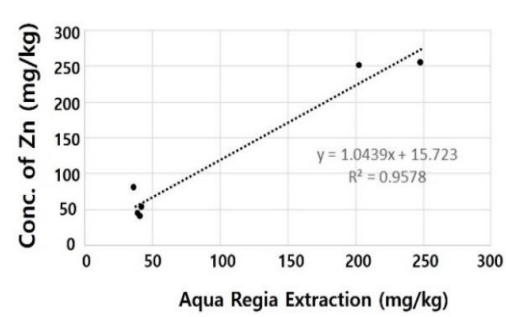

(b)

Figure 5. Correlation between aqua regia and sequential extraction for (a) $\mathrm{Cu}$ and (b) $\mathrm{Zn}$. 
Between July and September, the minimum and maximum average $\mathrm{Cu}$ concentrations were obtained from steps 1 and 5 of the sequential extraction method, respectively (Figure 6). $\mathrm{Cu}$ residuals extracted from step 5 amounted to 7.93 to $26.1 \mathrm{mg} / \mathrm{kg}$, (Figure 6a) corresponding to between $33.6 \%$ and $63.5 \%$ (Figure $6 \mathrm{c}$ ) of the total $\mathrm{Cu}$ concentration. Larger percentages of $\mathrm{Cu}$ residual were obtained from ND2 during July and August (63.53\% and 51.40\%) than from ND1 (49.79\% and 33.62\%). In contrast, this was reversed during September, where the percentage of $\mathrm{Cu}$ residual was higher at ND1 (43.63\%) than at ND2 (39.84\%). A large amount of $\mathrm{Cu}$ residual corresponds to low bioavailability and mobility of $\mathrm{Cu}$. Since the background concentration of $\mathrm{Cu}$ in river sediments in South Korea is $43.9 \mathrm{mg} / \mathrm{kg}$ [16,43], $\mathrm{Cu}$ residuals in the present sediment samples were likely derived from natural origins. Moreover, the $\mathrm{Cu}$ concentration bound to organic matters is much higher than that of other heavy metal bound to organics. This is because, particulate organic matter is one of the main ligands attachable to $\mathrm{Cu}[28,44-46]$. This also explains the significant concentrations of $\mathrm{Cu}$ extracted from fraction 4.

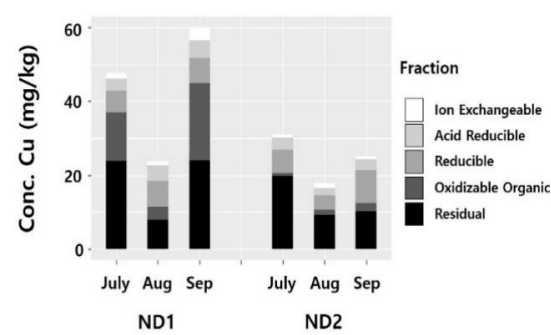

(a)

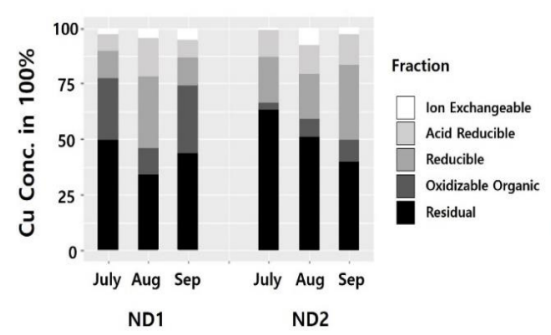

(c)

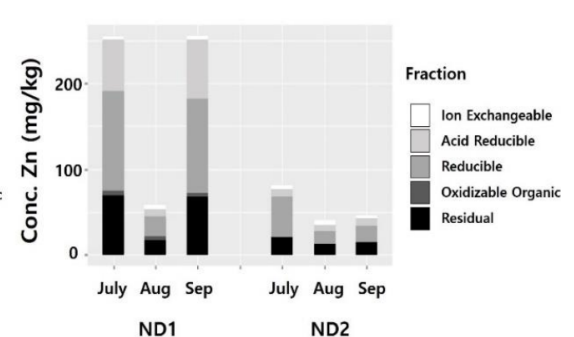

(b)

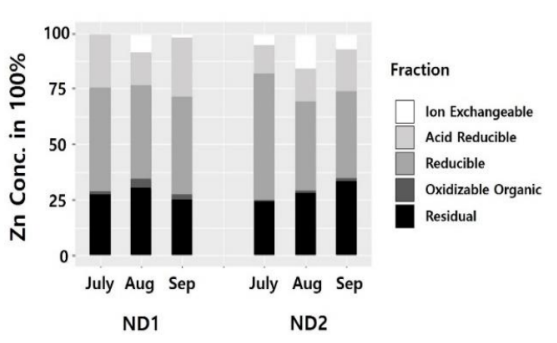

(d)

Figure 6. Results of sequential extraction: (1) Concentration of each fraction of sequential extraction for (a) $\mathrm{Cu}$ and (b) $\mathrm{Zn}$, (2) Concentration in each fraction of sequential extraction expressed as a percentage of the total concentration for (c) $\mathrm{Cu}$ and (d) $\mathrm{Zn}$.

The exchangeable fraction has the highest chance to leach back into water, which constitute the smallest portion of total $\mathrm{Cu}$. Ion exchangeable forms alone accounted for only 1.46 to $8.10 \%$ of the total concentration of $\mathrm{Cu}$. Therefore, it may not impact the water quality significantly. However, heavy metals bound to carbonates also have high bioavailability and impact the water body. These chemical forms typically arise due to anthropogenic input and are commonly referred to as nonresistant phases [28]. We note that the combination of exchangeable and carbonate forms represents 10.65 to $22.16 \%$ of the total $\mathrm{Cu}$ concentration. Together, these two forms may affect the water quality, despite the majority of the $\mathrm{Cu}$ concentration existing as residual $\mathrm{Cu}$.

The average concentration of leached $\mathrm{Zn}$ was greatest during its extraction in fraction 3, bound to iron and manganese, as shown in Figure 6, while the smallest amount of $\mathrm{Zn}$ was extracted in fraction 4 , bound to organic matters. Fraction 3 ranged between 16.10 and $117.05 \mathrm{mg} / \mathrm{kg}$ (Figure $6 \mathrm{~b}$ ), corresponding to between $38.9 \%$ and $56.4 \%$ of the total Zn concentration (Figure 6d). In July, the percentage of this fraction was higher at ND2 $(56.37 \%)$ than at ND1 (46.47\%). Conversely, the percentages were higher at ND1 during August and September (46.47\% and $42.57 \%$ ) than at ND2 (39.75\% and 38.90\%). Heavy metals bound to iron-manganese oxides along with metals bound to organics and residuals, are classified as resistant forms since they are readily incorporated into the sediment $[28,31]$. 
However, iron and manganese oxides may leach back into the water provided that specific circumstances are achieved, such as anaerobic conditions [47]. Therefore, $\mathrm{Zn}$ bound to iron-manganese oxides may leach and be taken up by aquatic animals during dry seasons with a stagnant overlying water body, which could represent a potential threat to the water body and aquatic ecosystem.

In contrast, the smallest fraction was comprised of $\mathrm{Zn}$ bound to organics including sulfides and organics that were extracted during fraction 4 . Along with the organic matter's preference toward $\mathrm{Cu}, \mathrm{Zn}$ adsorbed onto sulfides and organics are stable under anaerobic conditions but may dissolve under aerobic conditions [47]. Since high volumes of precipitation were recorded between July and September 2019, no thermocline was likely formed at the water body near the HCW [48]. In turn, this could have enabled the water at lower depths to maintain aerobic conditions. Under these circumstances, $\mathrm{Zn}$ adsorbed onto sulfides and organics may have leached back into the water, while iron-manganese oxides would have remained in the sediment.

The exchangeable fraction of $\mathrm{Zn}$ consisted of 0.62 to $16.30 \%$ of total $\mathrm{Zn}$. However, we note that the summed concentration of $\mathrm{Zn}$ bound to exchangeable and carbonates accounted for 18.44 to $30.99 \%$ of the total concentration of $\mathrm{Zn}$, indicating that $\mathrm{Zn}$ could affect the water quality.

\subsection{Risk Assessment Code}

The RAC is applied to assess the potential threats of heavy metals by evaluating heavy metal mobility and bioavailability $[34,35]$. Therefore, explaining the results using the RAC will provide a clearer evaluation regarding the concentrations of heavy metals extracted. The result of the RAC is shown in Figure 7. According to the RAC, $\mathrm{Cu}$ concentrations around the HCW has medium risk. On the other hand, Zn sample of August at ND2 poses a high risk to aquatic animals. Except for the August ND2 sample, Zn samples indicate that $\mathrm{Zn}$ poses a medium risk to aquatic animals. This shows that the $\mathrm{Cu}$ and $\mathrm{Zn}$ concentrations are not negligible, which indicates that both $\mathrm{Cu}$ and $\mathrm{Zn}$ have potential to deteriorate the quality of the water body. This suggests the necessity of continuous monitoring.

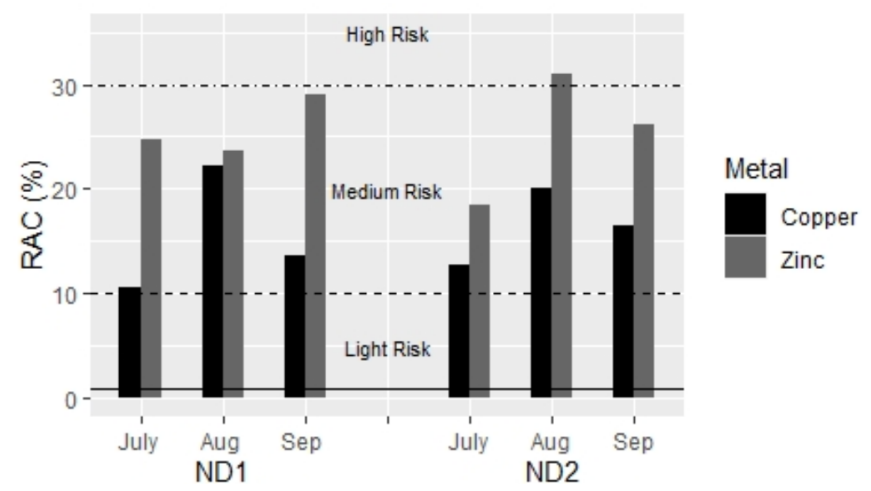

Figure 7. Risk Assessment Code (RAC) for $\mathrm{Cu}$ and Zinc in sediment samples from the HCW, analyzed by sequential extraction.

\subsection{Assessment of the Sediment Quality}

The heavy metal extraction results were compared with the standards published by NIER, Canada, and US EPA to assess the quality of our sediments. The sediment concentrations of $\mathrm{Cu}, \mathrm{Zn}$, and $\mathrm{Pb}$ were found to be $19.90-59.84 \mathrm{mg} / \mathrm{kg}$, 35.85-255.6 mg/kg, and $4.6-33.05 \mathrm{mg} / \mathrm{kg}$, respectively. According to the NIER's sediment quality standard, our $\mathrm{Zn}$ and $\mathrm{Pb}$ concentrations may be classified as grade 1 , while the $\mathrm{Cu}$ concentrations may be classified between grades 1 and 2 (Figure 8a). Although the $\mathrm{Cu}$ concentrations reached grade 2 in samples obtained during July and September at ND1, all other samples maintained a grade 1 classification. Therefore, $\mathrm{Cu}$ contamination is not expected to affect the river's benthos [16]. 


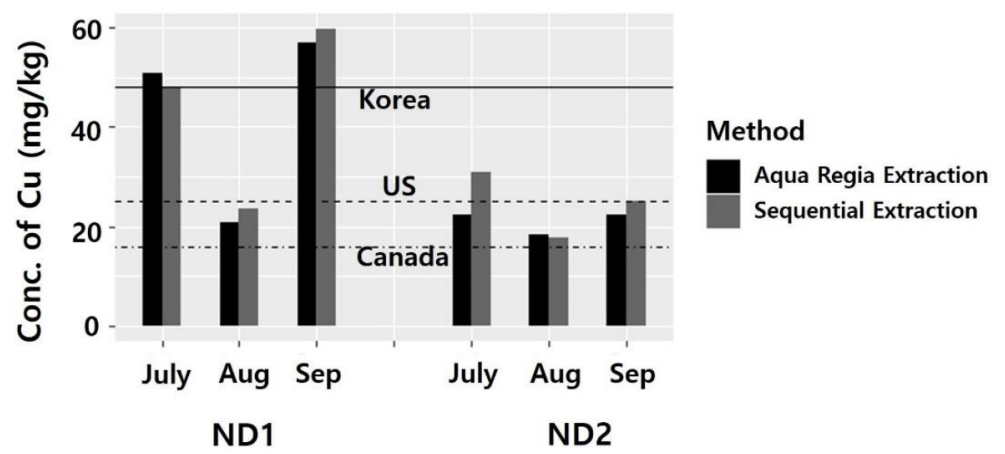

(a)

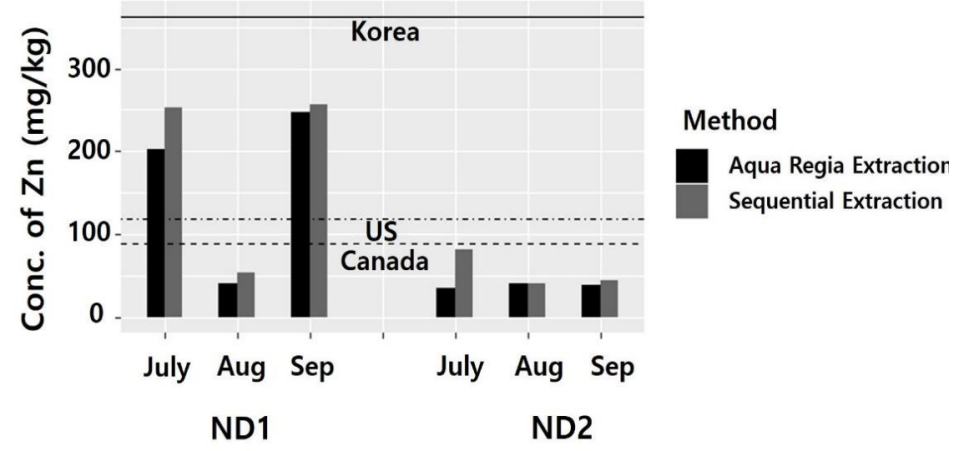

(b)

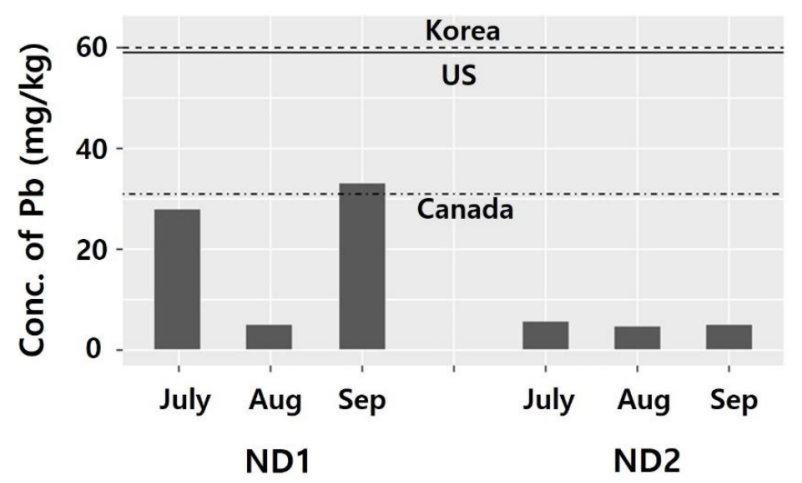

(c)

Figure 8. Sediment heavy metal standard of (a) Korea NIER, (b) Canada, and (c) US EPA.

Our data were further assessed according to the international standards for sediment quality as set by the Canada and US EPA. According to the former, all $\mathrm{Cu}$ concentrations, as well as the Zn concentrations in July and September (sampled at ND1), and the Pb concentrations in September (sampled at ND1) exceeded the "Lowest Effect Level" (LEL) standard, as shown in Figure 8b [17]. Metals concentrations that exceed LEL values risk impacting the aquatic ecosystem. Similarly, $\mathrm{Cu}$ and $\mathrm{Pb}$ concentrations from several samples exceeded the non-polluting standards set by the US EPA [18], as shown in Figure 8c, which indicates potential threats to the aquatic ecosystem.

\section{Conclusions}

In this study, aqua regia extraction and sequential extraction were employed to quantify the heavy metal contamination in sediments from the HCW of the Nakdong River and evaluate possible contamination sources. The weir's impact on heavy metal sedimentation was studied, and the sediment quality was assessed through comparisons with heavy metal standards published by the NIER, Canada, and US EPA. Our experimental results demonstrated higher concentrations of $\mathrm{Cu}, \mathrm{Zn}$, and $\mathrm{Pb}$ in the sediment during July 
and September than in August. Furthermore, higher metal concentrations were found in samples collected closer to the weir, ND1. There was no difference between heavy metal concentrations measured by aqua regia extraction and sequential extraction, as supported by correlation analysis. Since the concentration of heavy metals was higher at ND1 than at ND2, the result indicates that the weir decreases the water velocity and promotes metal sedimentation. The correlation between TOC concentration and heavy metal concentrations also suggests the reliability of the experiment. Sequential extraction showed that naturally occurring $\mathrm{Cu}$ residuals comprised the most considerable fraction of total $\mathrm{Cu}$ contamination. In contrast, iron-manganese oxides comprised the most considerable portion of $\mathrm{Zn}$ contamination, which is assumed to be formed through human activity. Similarly, the result of RAC indicated that both $\mathrm{Cu}$ and $\mathrm{Zn}$ might cause medium risk on water body and aquatic ecosystem. Additionally, the sediment quality was assessed according to the NEIR, Canadian, and US EPA guidelines. Based on the NIER criteria, only the $\mathrm{Cu}$ contamination in samples taken from location ND1 during July and September was expected to impact the aquatic ecosystem. The other metals were not expected to affect the aquatic ecosystem of the river. However, the application of the Canadian, and US EPA standards found that the $\mathrm{Cu}$ concentrations in all samples were expected to impact the aquatic ecosystem. Furthermore, Zn concentrations in July and September (sampled at $\mathrm{ND1}$ ) and the Pb concentrations in September (sampled at ND1) were also sufficient to potentially impact the aquatic ecosystem. Heavy metal contamination in the sediments has a negative impact on the aquatic ecosystem which might be enhanced by the installation of a weir through river flow stagnation. Based on the results of this study, with respect to water quality management, it is necessary to continue monitoring the levels of heavy metal contamination to manage the sediment quality around the weir.

Author Contributions: Data curation, H.W.S., S.H.S. and H.O.; Formal analysis, H.O.; Methodology, H.W.S. and S.H.S.; Project administration, J.H.C.; Supervision, J.H.C.; Writing-original draft, H.W.S.; Writing-review and editing, J.H.C. All authors have read and agreed to the published version of the manuscript.

Funding: This research was supported by the Basic Science Research Program through the National Research Foundation of Korea (NRF) funded by the Ministry of Education (2016R1D1A1B04934910 and 2018R1A6A1A08025520).

Informed Consent Statement: Not applicable.

Data Availability Statement: Data available on request due to the restriction of privacy. The data presented in this study are available on request from the corresponding author. The data are not publicly available due to we also need to use these data for further research, involving privacy.

Conflicts of Interest: The authors declare no conflict of interest.

\section{References}

1. Machado, C.S.; Alves, R.I.S.; Fregonesi, B.M.; Tonani, K.A.A.; Martinis, B.S.; Sierra, J.; Nadal, M.; Domingo, J.L.; Segura-Munoz, S. Chemical contamination of water and sediments in the Pardo River, Sao Paulo, Brazil. Procedia Eng. 2016, 162, 230-237. [CrossRef]

2. Atieh, M.A.; Ji, Y.; Kochkodan, V. Metals in the environment: Toxic metals removal. Bioinorg. Chem. Appl. 2017, 2017, 1-2. [CrossRef]

3. Park, J.; Lee, S.; Lee, E.; Noh, H.; Seo, Y.; Lim, H.H.; Shin, H.S.; Lee, I.; Jung, H.; Na, T.; et al. Probabilistic ecological risk assessment of heavy metals using the sensitivity of resident organisms in four Korean rivers. Ecotox. Environ. Saf. 2019, 183, 1-10. [CrossRef]

4. Nguyen, B.T.; Do, D.D.; Nguyen, T.X.; Nguyen, V.N.; Nguyen, D.T.P.; Nguyen, M.H.; Troung, H.T.T.; Dong, H.P.; Le, A.H.; Bach, Q.-V. Seasonal, spatial variation, and pollution sources of heavy metals in the sediment of the Saigon River, Vietnam. Enviorn. Pollut. 2020, 256,1-12. [CrossRef]

5. Xie, Q.; Qian, L.; Liu, S.; Wang, Y.; Zhang, Y.; Wang, D. Assessment of Long-term effects from cage culture practices on heavy metal accumulation in sediment and fish. Ecotox. Environ. Saf. 2020, 194, 1-7. [CrossRef] [PubMed]

6. Kang, M.K.; Choi, I.Y.; Park, J.H.; Choi, J.H. Investigation of the effect of weirs construction in the Han River on the characteristics of sediments. J. Korean Soc. Environ. Eng. 2012, 34, 597-603. [CrossRef]

7. Yang, Y.M.; Shim, M.J.; Oh, D.Y.; Khan, J.B.; Lee, J.B.; Lee, S.H.; Park, S.J. Spatial distribution of heavy metals in Geum River after weirs construction. Korean J. Environ. Agric. 2015, 34, 64-68. [CrossRef] 
8. Moon, G.; Park, H.; Yoo, K.; Jha, M.K.; Kim, J.Y. The Determination of chemical forms of heavy metals in shooting area contaminated soil using Sequential Extraction Method. J. Soil Groundw. Environ. 2015, 20, 111-116. [CrossRef]

9. Kim, M.J.; Jang, M.J. A study on sequential extraction of heavy metals from marine dredged sediment at Busan New Port. J. Korean Soc. Environ. Eng. 2011, 33, 93-102. [CrossRef]

10. Rosado, D.; Usero, J.; Morillo, J. Ability of 3 extraction method (BCR, Tessier and protease K) to estimate bioavailable metals in sediments from Huelva estuary (Southwestern Spain). Mar. Pollut. Bull. 2016, 102, 65-71. [CrossRef]

11. Tessier, A.; Campbell, P.G.; Bisson, M. Sequential extraction procedure for the speciation of particulate trace metals. Anal. Chem. 1979, 51, 844-851. [CrossRef]

12. Scheckel Kirk, G.; Impellitteri, C.A.; Ryan, J.A.; McEvoy, T. Assessment of a Sequential Extraction Procedure for Perturbed Lead-Contaminated samples with and without Phosphorus Amendments. Environ. Sci. Technol. 2003, 37, 1892-1898. [CrossRef]

13. Pandey, L.K.; Park, J.; Son, D.H.; Kim, W.; Islam, M.S.; Choi, S.; Lee, H.; Han, T. Assessment of metal contamination in water and sediments from major rivers in South Korea from 2008 to 2015. Sci. Total Environ. 2019, 651, 323-333. [CrossRef]

14. Kim, S.; Ahn, J.; Jung, K.; Lee, K.; Kwon, H.; Shin, D.; Yang, D. Contamination Assessment of Heavy Metals in River Sediments (For the Surface Sediments from Nakdong River). J. Korean Soc. Water Environ. 2017, 33, 460-473.

15. Kayembe, J.M.; Sivalingam, P.; Salgado, C.D.; Maliani, J.; Ngelinkto, P.; Otamonga, J.P.; Mulaji, C.K.; Mubedi, J.I.; Pote, J. Assessment of water quality and time accumulation of heavy metals in the sediments of tropical urban rivers: Case of Bumbu River and Kokolo Canal, Kinshasa City, Democratic Republic of the Congo. J. Afr. Earth Sci. 2018, 147, 536-543. [CrossRef]

16. National Institute of Environmental Research. Baseline Concentrations of Heavy Metals in River Sediments in Korea; Ministry of Environment: Sejong, Korea, 2011.

17. Canadian Council of Ministers of the Environmental Protection. Protocol for the Derivation of Canadian Sediment Quality Guidelines for the Protection of Aquatic Life; Report CCME; EPA-98E; Canadian Council of Ministers of the Environmental Protection: Winnipeg, MB, Canada, 1995.

18. United States Environmental Protection Agency. Protocol for Developing Sediment TMDLs; EPA 841-B-99-004; United States Environmental Protection Agency: Washington, DC, USA, 1999.

19. Korea Water Resources Corporation. Available online: https://www.water.or.kr/realtime/sub01/sub01/mult.do?s_mid=1326 \&seq=1408\&p_group_seq=1407\&menu_mode=3 (accessed on 8 February 2021).

20. Zhao, Z.; Liu, G.; Liu, Q.; Huang, C.; Li, H. Studies on the spatiotemporal variability of river water quality and its relationships with soil and precipitation: A case study of the Mun River Basin in Thailand. Int. J. Environ. Res. Public Health 2018, 15, 2466. [CrossRef]

21. Lee, M.H.; Jung, H.J.; Kim, S.H.; An, S.U.; Choi, J.H.; Lee, H.J.; Huh, I.A.; Hur, J. Potential linkage between sediment oxygen demand and pore water chemistry in weir-impounded rivers. Sci. Total Environ. 2018, 619-620, 1608-1617. [CrossRef] [PubMed]

22. Algul, F.; Beyhan, M. Concentrations and sources of heavy metals in shallow sediments in Lake Bafa, Turkey. Sci. Rep. 2020, 10, 11782. [CrossRef] [PubMed]

23. Vasiliu, D.; Bucse, A.; Lupascu, N. Assessment of the metal pollution in surface sediments of coastal Tasaul Lake (Romania). Envrion. Monit. Assess. 2020, 192, 749. [CrossRef] [PubMed]

24. Folk, R.L.; Ward, W.C. Brazos River Bar: A Study in the Significance of Grain Size Parameters. J. Sediment. Petrol. 1957, $27,3-26$. [CrossRef]

25. Cheong, D.; Jung, H.M. Change of sedimentary facies of the Soyang Lake sediments and its effects on the environmental sedimentology since the construction of the Soyang River Dam. J. Geol. Soc. Korea 2006, 42, 199-234.

26. International Standard Organization. ISO 11466 Soil Quality-Extraction of Trace Elements Soluble in Aqua Regia; International Standard Organization: Geneva, Switzerland, 1995.

27. Scancar, J.; Milacic, R.; Horvat, M. Comparison of various digestion and Extraction procedures in analysis of heavy metals in sediment. Water Air Soil Pollut. 2000, 118, 87-99. [CrossRef]

28. Yap, C.K.; Ismail, A.; Tan, S.G.; Omar, H. Concentrations of $\mathrm{Cu}$ and $\mathrm{Pb}$ in the offshore and Intertidal sediments of the west coast of Peninsular Malaysia. Environ. Int. 2002, 28, 467-479. [CrossRef]

29. Yong, R.N.; Yaacob, W.Z.W.; Bentley, S.P.; Harris, C.; Tan, B.K. Partitioning of heavy metals on soil samples from column tests. Eng. Geol. 2001, 60, 307-322. [CrossRef]

30. Hwang, S.S.; Lee, N.S.; Namkoong, W. The Extraction Characteristics of Metal-contaminated Soil by Soil Washing. J. Korean Soc. Environ. Eng. 2005, 27, 1072-1080.

31. Li, X.; Coles, B.J.; Ramsey, M.H.; Thornton, I. Sequential Extraction of Soils for Multielement Analysis by ICP-AES. Chem. Geol. 1995, 124, 109-123. [CrossRef]

32. Hwang, K.Y.; Park, S.Y.; Baek, W.S.; Jung, J.H.; Kim, Y.H.; Shin, W.S.; Lee, N.J.; Hwang, I. Speciation and Leaching Potential of Heavy Metals in Sediments of Nakdong River. J. Korean Soc. Water Wastewater 2007, 21, 113-122.

33. Bolan, N.; Naidu, R.; Parkn, J.; Choppala, G. Solute Interactions in Soils in Relation to Heavy Metal Bioavailability and Remediation of the Environment. Korean J. Soil. Sci. Fert. 2009, 10, 216-222.

34. Zhang, G.; Bai, J.; Xiao, R.; Zhao, Q.; Jia, J.; Cui, B.; Liu, X. Heavy metal fractions and ecological risk assessment in sediments from urban, rural and reclamation-affected rivers of the Pearl River Estuary, China. Chemosphere 2017, 184, 278-288. [CrossRef] 
35. Yang, K.; Zhang, T.; Shao, Y.; Tian, C.; Cattle, S.R.; Zhu, Y.; Song, J. Fractionation, Bioaccessibility, and Risk Assessment of Heavy Metals in the Soil of an Urban Recreational Area Amended with Composted Sewage Sludge. Int. J. Environ. Res. Public Health 2018, 15, 613. [CrossRef]

36. Kim, S.; Yang, D.S.; Kim, S.Y. Distribution of metal contamination and grain size in the sediments of Nakdong River, Korea. Environ. Monit. Assess. 2020, 192, 1-15. [CrossRef] [PubMed]

37. Lee, H.J.; Park, H.K.; Cheon, S.U. Effects of Weir Construction on Phytoplankton Assemblages and Water Quality in a Large River System. Int. J. Environ. Res. Public Health 2018, 15, 2348. [CrossRef]

38. Ri, C.S. Analysis of water quality and heavy metals for surface water and sediments of upstream and midstream in Nakdong River. J. Korean Chem. Soc. 2000, 44, 547-555.

39. Hwang, S.C.; Jeong, S.U.; Park, W.W.; Kim, W.S.; Lee, B.H.; Park, H.J. A study on the relation between riverbed structure and pollutant concentration in downstream of Nakdong River. J. Environ. Sci. Intern. 1997, 6, 513-520.

40. Ramos, T.B.; Gonçalves, M.C.; Branco, M.A.; Brito, D.; Rodrigues, S.; Sánchez-Pérez, J.; Sauvage, S.; Prazeres, A.; Martins, J.C.; Fernandes, M.L.; et al. Sediment and nutrient dynamics during storm events in the Enxoé temporary river, southern Portugal. CATENA 2015, 127, 177-190. [CrossRef]

41. Coquery, M.; Welbourn, P.M. The relationship between metal concentration and organic matter in sediments and metal concentration in the aquatic macrophyte Eriocaulon septangulare. Water Res. 1995, 29, 2094-2102. [CrossRef]

42. Aleksander-Kwaterczak, U.; Kostka, A.; Leśniak, A. Multiparameter assessment of select metal distribution in lacustrine sediments. J. Soils Sediments 2021, 21, 512-529. [CrossRef]

43. Ahn, J.M.; Im, T.H.; Kim, S.; Lee, S.; Kim, S.; Lee, K.C.; Kim, Y.S.; Yang, D.S. Evaluating sediment heavy metal pollution level and monitoring network representativeness at the upstream points of the Ganajeong-Goryeong Weir in the Nakdong River. J. Environ. Sci. Intern. 2018, 27, 477-488. [CrossRef]

44. Li, J.L.; He, M.; Han, W.; Gu, Y.F. Availability and mobility of heavy metal fractions related to the characteristics of the coastal soils developed from alluvial deposits. Environ. Monit. Assess. 2009, 158, 459-469. [CrossRef]

45. Bibby, R.L.; Webster-Brown, J.G. Trace metal adsorption onto urban stream suspended particulate matter (Auckland region, New Zealand). Appl. Geochem. 2006, 21, 1135-1151. [CrossRef]

46. Yu, K.C.; Tsai, L.J.; Chen, S.H.; Ho, S.T. Correlation analyses on binding behavior of heavy metals with sediment matrices. Water Res. 2001, 35, 2417-2428. [CrossRef]

47. Kang, S.H.; Ahn, J.Y.; Hwang, K.Y.; Seo, J.Y.; Kim, J.G.; Song, H.C.; Yim, S.B.; Hwang, I.S. Stabilization of heavy metal-contaminated mine tailings using phosphate fertilizers and red mud. J. Soil Groundw. Environ. 2011, 16, 31-41. [CrossRef]

48. Na, E.H.; Park, S.; Kim, J.; Im, S.; Kim, K. A Study on Spatial and Temporal Patterns of Water Quality in the Middle Area of the Nakdong River, Korea. J. Korean Soc. Water Environ. 2015, 31, 723-731. [CrossRef] 